\title{
Real Time Implementation of DSP based Fuzzy Logic Controller for Speed Control of BLDC Motor
}

\author{
G.Sakthivel \\ T.S.Anandhi \\ Reader Prof \& Head \\ S.P.Natarjan \\ Lecturer (SG) \\ Dept of E\&I . Annamalai University, Annamalainagar, Chidambaram, INDIA
}

\begin{abstract}
The brushless DC motor (BLDCM) is receiving wide attention for industrial applications because of their high torque density, high efficiency and small size. The advantages of BLDC motor have led to their wide spread used in variable speed drives. The objective of the paper is to develop an intelligent speed control algorithm for BLDC motor in Vissim software which is an environment for model based development of embedded controller for Texas instruments DSPs. In this paper TMSC320F2812 DSP is used as the controller necessary signal conditioning components are used to ensure high processing speed and precision in the overall control system. The implemented system has a fast response with small overshoot and zero steady state error compared to conventional PI Controller.
\end{abstract}

Keywords: PI Controller; BLDC motor; Fuzzy Logic Controller, Vissim.

\section{INTRODUCTION}

Since the late 1980's new design concept of permanent magnet brushless motors has been developed. The permanent magnet brushless motor can be classified upon to the back-EMF waveform, where it can be operated in either brushless $\mathrm{AC}$ (BLAC) or brushless DC (BLDC) modes. In modern electrical machines industry productions the brushless direct current (BLDC) motors are rapidly gaining popularity. BLDC motors are used in industries such as Appliances, HVAC industry, medical, electric traction, road vehicles, aircrafts, military equipment, hard disk drive, etc. Comparing BLDC motors with DC motors, the DC motor have high starting torque capability, smooth speed control and the ability to control their torque and flux easily and independently. In the DC motor, the power losses occur mainly in the rotor which limits the heat transfer and consequently the armature winding current density, while in BLDC motor the power losses are practically all in the stator where heat can be easily transferred through the frame, or cooling systems can be used specially in large machines. In general the induction motor has many advantages as: their simplest construction, simple maintenance, low price and reliability. Furthermore, the disadvantages of induction machines make the BLDC motors more efficient to use and become more attractive option than induction motors. Some of the disadvantages of induction machines are poor dynamic characteristics, lower torque at lower speeds and lower efficiency[1].
Permannent magnet alternating current(PMAC) are synchronous motors that have permanent magnets mounted on the rotor and polyphase ,usally three phase armature windings loacted on the stator.since the field is provided by the permanent magnets the PMAC motor has higer efficency than induction or reluctance motor.In general PMAC motors are categorized into two types based on the back emf.In modern elctrical machine industries production of BLDC motors are rapidly gaining popularity .The BLDC drive system is based on the feedback of rotor position, which is not continous as with the PMSM ,but rather obtained at $60^{\circ}$ electrical degrees for commutation of the phase currents.BLDC requries that quasirectangular shaped currents are fed into the machine.Alternatively, the voltage may be applied to the motor every $120^{\circ}$ with a current limit to hold the currents within the motors capabilities . Because the phase currents are exicted in synchronism with the constant part of the back emf,constant torque is generated .The paper is organised as follows: Section II explains the construction and working principle of BLDC motor, Section III introduces the Digital fuzzy logic controller section IV shows experimental setup.Results are detailed in the sectionV.

\section{CONSTRUCTION AND OPERATING PRINCIPLE}

BLDC motors are a type of synchronous motor. This means the magnetic field generated by stator and magnetic field generated by the rotor rotate at the same frequency. BLDC motor do not experience the "slip" that is normally seen in induction motors.A brushless motor is constructed with a permanent magnet rotor and wire wound stator poles. Electrical energy is converted to mechanical energy by the magnetic attractive forces between the permanent magnet rotor and a rotating magnetic field induced in the wound stator poles. Figure 1 shows the construction

of

BLDC motor.

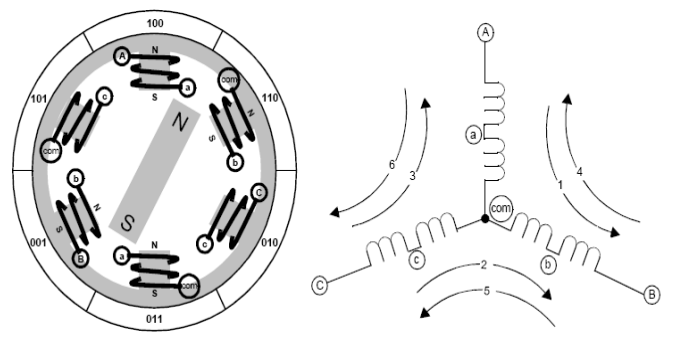

Figure 1 construction of BLDC motor 


\subsection{Stator}

The stator of a BLDC motor consists of stacked steel laminations with windings placed in the slots that are axially cut along the inner periphery. Traditionally ,the stator resembles that of an induction motor ,how where ,three windings are distributed in a different manner .Most BLDC motors have three stator windings connected in star fashion .Each of these windings are constructed with numerous coils interconnected to form a winding. One or more coils are placed in the slots and they are interconnected to make a winding[1]. Each of these windings are distributed over the stator periphery to form an even numbers of poles.

\subsection{Rotor}

The rotor is made of permanent magnet and can vary from two to eight pole pairs with alternate north and south poles. Based on the required magnetic field density in the rotor, the proper magnetic materials is chosen to make the rotor. Ferrite magnts are traditionally used to make permanent magnets .

\subsection{Hall sensors:}

The commutation of a BLDC motor is controlled electronically. To rotate the BLDC motor, the stator windings should be energized in sequence .It is important to understand which winding will be energized following the energizing sequence. Rotor position is sensed using Hall Effect sensors embedded in to the stator. Most BLDC motors have three Hall sensors embedded into the stator on the non-driving end of the motor. Whenever the rotor magnetic poles pass near the hall sensors, they give a high or low signal, indicating the $\mathrm{N}$ or $\mathrm{S}$ pole is passing near the sensors. Based on the combination of these three Hall sensors signals, the exact sequence of commutation can be determined.

\subsection{Theory of operation}

Each commutation sequence has one of the windings energized to positive power, the second winding is negative and the third winding is in a non - energized condition. Torque is produced because of the interaction between the magnetic field generated by the stator coils and the permanent magnets. Ideally, the peak torque occurs when these two fields are at $90^{\circ}$ to each other and falls off as the fields move together. In order to keep the motor running, the magnetic field produced by the windings should shift position , as the rotor moves to catch up with the stator field.

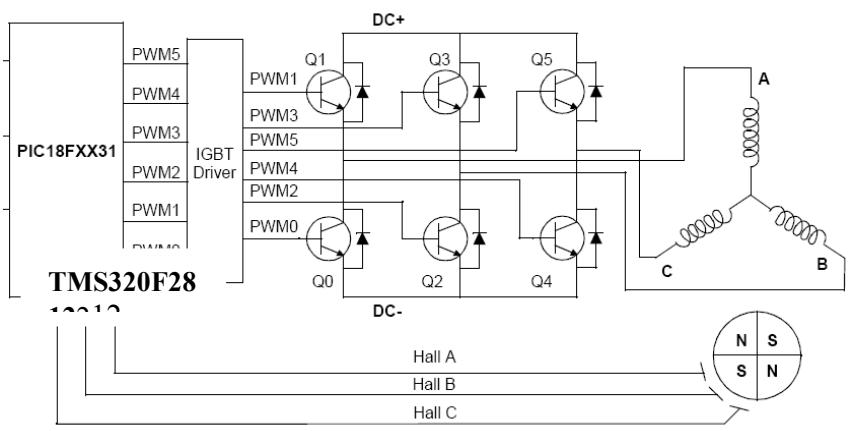

FIGURE 2: Control Block Diagram

\subsection{Commutation sequence}

Every 60 electrical degrees of rotation, one of the Hall sensors changes the state. Given this, it takes six steps to complete an electrical cycle. In synchronous, with every 60 electrical degrees, the phase current switching should be updated. However, one electrical cycle may not correspond to a complete mechanical revolution of the rotor. The number of electrical cycles to be repeated to complete a mechanical rotation is determined by the rotor pole pairs. For each rotor pole pairs, one electrical cycle is completed. So, the number of electrical cycles/rotations equals the rotor pole pairs. Figure 2 shows a block diagram of the controller used to control a BLDC motor. Q0 to Q5 are the power switches controlled by the TMS320F281 DSP Processor. Based on the motor voltage and current ratings, these switches can be MOSFETs, or IGBTs, or simple bipolar transistors. Table 1 and Table 2 show the sequence in which these power switches should be switched based on the Hall sensor inputs, A, B and C. Table 1 is for clockwise rotationof the motor and Table 2 is for counter clockwise motor rotation. When deriving a controller for a particular motor, the sequence defined by the motor manufacturer should be followed .Referring to Figure 9, if the signals marked by PWMx are switched ON or OFF according to the sequence,the motor will run at the rated speed. This is assuming that the DC bus voltage is equal to the motor rated voltage,plus any losses across the switches. To vary the speed, these signals should be Pulse Width Modulated (PWM) at a much higher frequency than the motor frequency Another advantage of having PWM is that, if the DC bus voltage is much higher than the motor rated voltage, the motor can be controlled by limiting the percentage of PWM duty cycle corresponding to that of the motor rated voltage.This adds flexibility to the controller to hook up motors with different rated voltages and match the average voltage output by the controller, to the motor rated voltage, by controlling the PWM duty cycle. There are different approaches of controls. If the PWM signals are limited in the microcontroller, the upper switches can be turned on for the entire time during the corresponding sequence and the corresponding lower switch can be controlled by the required duty cycle on PWM. Through Visim software speed reference is given, based on this ,controller calculates the PWM duty cycle

\begin{tabular}{|c|c|c|c|c|c|c|c|c|}
\hline \multirow[t]{2}{*}{ Sequence } & \multicolumn{3}{|c|}{$\begin{array}{c}\text { Hall sensor } \\
\text { input }\end{array}$} & \multicolumn{2}{|c|}{ Active PWMs } & \multicolumn{3}{|c|}{ Phase current } \\
\hline & $\mathbf{A}$ & B & C & & & $\mathbf{A}$ & B & C \\
\hline 1 & 0 & 0 & 1 & PWM1(Q1) & PWM4(Q4) & $\mathrm{DC}+$ & off & DC- \\
\hline 2 & 0 & 0 & 0 & PWM1(Q1) & PWM2(Q2) & $\mathrm{DC}+$ & DC- & off \\
\hline 3 & 1 & 0 & 0 & PWM5(Q5) & PWM2(Q2) & off & DC- & DC+ \\
\hline 4 & 1 & 1 & 0 & PWM5(Q5) & PWM0(Q0) & DC- & off & DC+ \\
\hline 5 & 1 & 1 & 1 & PWM3(Q3) & PWM0(Q0) & DC- & DC+ & off \\
\hline 6 & 0 & 1 & 1 & PWM3(Q3) & PWM4(Q4) & off & $\mathrm{DC}+$ & DC- \\
\hline
\end{tabular}

Table 1: Sequence for rotating the motor in clockwise direction.

\begin{tabular}{|c|c|c|c|c|c|c|c|c|}
\hline \multirow{3}{*}{ Sequence } & \multicolumn{3}{|c|}{$\begin{array}{c}\text { Hall sensor } \\
\text { input }\end{array}$} & \multicolumn{4}{|c|}{ Active PWMs } & \multicolumn{3}{c|}{ Phase current } \\
\cline { 2 - 9 } & A & B & C & \multicolumn{2}{|c|}{} & A & B & C \\
\cline { 3 - 10 } & 0 & 1 & 1 & PWM1(Q5) & PWM4(Q2) & off & DC- & DC+ \\
\hline 1 & 1 & 1 & 1 & PWM1(Q1) & PWM2(Q2) & DC+ & DC- & off \\
\hline 2 & 1 & 1 & 0 & PWM5(Q1) & PWM2(Q4) & DC+ & off & DC- \\
\hline 3 & 1 & 0 & 0 & PWM5(Q3) & PWM0(Q4) & off & DC+ & DC- \\
\hline 4 & 0 & 0 & 0 & PWM3(Q3) & PWM0(Q0) & DC- & DC+ & off \\
\hline 5 & 0 & 0 & 1 & PWM3(Q5) & PWM4(Q0) & DC- & off & DC- \\
\hline 6 & & & & & & & \\
\hline
\end{tabular}


Table 2: Sequence for rotating the motor in anticlockwise direction.

\subsection{Closed-Loop Control}

The speed can be controlled in a closed loop by measuring the actual speed of the motor. The error in the set speed and actual speed is calculated. A Proportional plus Integral (P.I.) controller can be used to amplify the speed error and dynamically adjust the PWM duty cycle. For low-cost, low-resolution speed requirements, the Hall signals can be used to measure the speed feedback. A timer from the TMS320f281 can be used to count between two Hall transitions. With this count, the actual speed of the motor can be calculated.[2]For high-resolution speed measurements, an optical encoder can be fitted onto the motor, which gives two signals with 90 degrees phase difference. Using these signals, both speed and direction of rotation can be determined. Also, most of the encoders give a third index signal, which is one pulse per revolution. This can be used for positioning applications. Optical encoders are available with different choices of Pulse Per Revolution (PPR), ranging from hundreds to thousands.

\subsection{Speed Control}

Commutation ensures proper rotor rotation of the BLDC motor, while the motor speed depends only on the amplitude of the applied voltage, which is adjusted by using the PWM technique. The required speed is controlled by a speed controller, implemented as a conventional Proportional-Integral (PI) controller. The difference between the actual and required speed is input to the PI controller and, based on this difference, the PI controller controls the duty cycle of PWM pulses which corresponds to the voltage Figure 3 shows the Visim Block Diagram for the fuzzy logic controller with BLDC motor

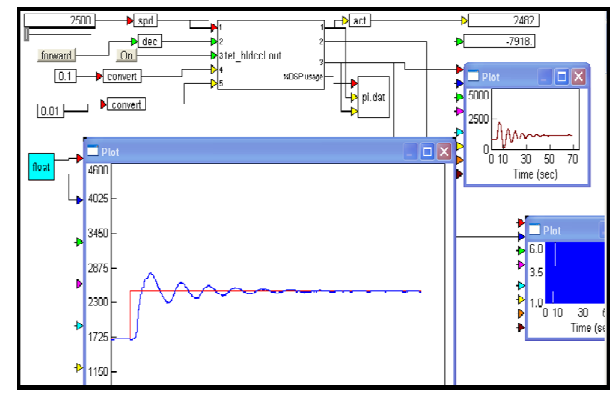

Figure 3:Visim Block Diagram for the fuzzy logic controller with BLDC motor

\subsection{Overview of TMSC $320 F 2812$}

The CPU is a low-cost 32-bit fixed-point digital signal processor (DSP). This device draws from the best features of digital signal processing; reduced instruction set computing (RISC); and microcontroller architectures, firmware, and tool sets. The DSP features include a modified Harvard architecture and circular addressing. The RISC features are single-cycle instruction execution, register-to-register operations, and modified Harvard architecture (usable in Von Neumann mode). The microcontroller features include ease of use through an intuitive instruction set, byte packing and unpacking, and bit manipulation. The modified Harvard architecture of the CPU enables instruction and data fetches to be performed in
parallel.[4]The CPU can read instructions and data while it writes data simultaneously to maintain the single-cycle instruction operation across the pipeline. The CPU does this over six separate address/data buses.

\section{Features of TMS320F2812}

High-Performance Static CMOS Technology

High-Performance 32-Bit CPU

Three 32-Bit CPU-Timers

Motor Control Peripherals

- Two Event Managers (EVA, EVB)

12-Bit ADC, 16 Channels

-2 x 8 Channel Input Multiplexer

Up to 56 General Purpose I/O (GPIO) Pins

On-Chip Memory

- Flash Devices: Up to $128 \mathrm{~K}$ x 16 Flash

(Four $8 \mathrm{~K}$ x 16 and Six $16 \mathrm{~K}$ x 16 Sectors)

- ROM Devices: Up to $128 \mathrm{~K}$ x 16 ROM

\section{Fuzzy Logic control}

There are a number of reasons for using fuzzy logic in the speed control of BLDC motor, the primary advantage being the flexibility offered by fuzzy logic. The following sections describe the development of FLC for speed control of BLDC motor. The present design utilises three types of membership functions $-\Gamma$-function, $L$-function and $\Lambda$-function. These functions have been proven to produce good results for control applications and can be easily implemented into hardware. The universe of discourse of the input variables is partitioned into five fuzzy sets or linguistic values ( $B 1$ to $B 5$ ), while the output variable can take any of the nine linguistic values ( $D 1$ to $D 9)$. Graphical representations of the membership functions are shown in Figure 4. and Figure 5.

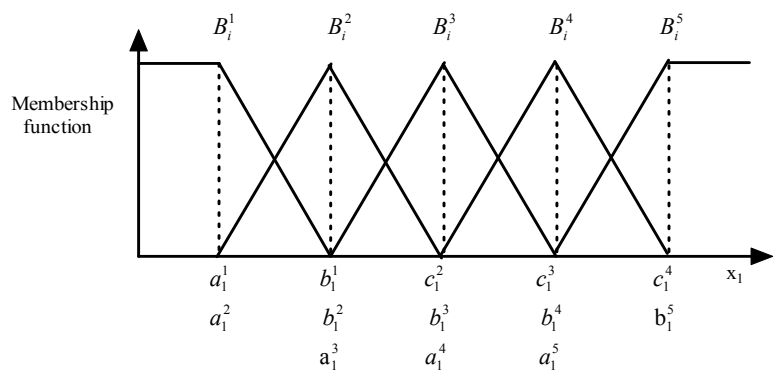

Figure 4 Membership function of input variable(error and change in error)

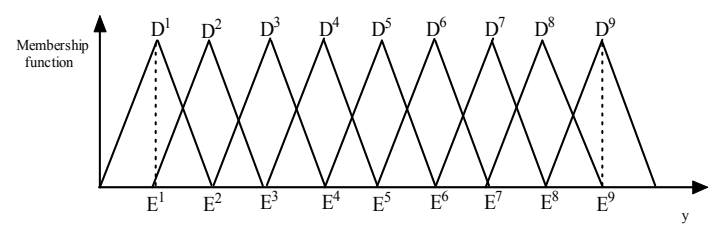

Figure 5 Membership function of output variable

Each input variable a membership function relating to the fuzzy sets, $\left(B_{i}^{1}\right.$ to $\left.B_{i}^{5}\right)$. It has to be pointed out that in these equations, $B_{i}^{j}$ is used to denote the linguistic value as well as membership 
function, while membership function using $\mu_{\mathrm{Bi}, \mathrm{j}}\left(x_{i}\right)$. The universe of discourse of the output variable is divided into nine linguistic Values. The membership functions of the output values are intentionally made to be symmetrical, as this will simplify the defuzzification computation. E1 to E9 are the mean of each function and act as the weightings to the weighted average method of defuzzification.Each input variable can take any of the five linguistic values, therefore 25 (= 5 X 5) rules are formulated. The rules have the typical fuzzy rule structure, using linguistic variables in both the antecedent and consequent, and are expressed in IF-THEN manner. They map the input states onto 25 output conditions ( $C 1$ to $C 25$ ). The fuzzy rules have the general form,

$\mathrm{R}^{\mathrm{K}}$ : IF $\mathrm{x}_{1}$ is $\mathrm{A}_{1}^{\mathrm{k}}$ AND $\mathrm{x}_{2}$ is $\mathrm{A}_{2}^{\mathrm{k}}$,THEN $\mathrm{y}$ is $\mathrm{C}^{\mathrm{K}}$ (1)

Then the rule base can be represented by a fuzzy associative memory (FAM) table (Table 1).

The FLC design in this work incorporates Mamdani's implication method of inference, which is one of the most popular methods in fuzzy control applications. In essence, Mamdani's implication for the fuzzy rule of (4) is given by

$$
\mu_{\mathrm{c}}(\mathrm{y})=\max _{\mathrm{k}}\left[\min \left[\mathrm{\mu}_{\mathrm{A}_{1}^{\mathrm{k}}}\left(\mathrm{x}_{1}\right), \mu_{\mathrm{A}_{2}^{\mathrm{k}}}\left(\mathrm{x}_{2}\right)\right]\right] \mathrm{k}=1,2, \ldots .25
$$

The implication has a simple min-max structure which makes it easy to incorporate into hardware. The block diagram in Figure. 6 provides an overview of the controller's internal structure. Two input variables are fuzzified, producing the corresponding linguistic values and membership functions $\left(B_{i}^{j}\right)$. The first phase of Mamdani's implication involves minoperation since the antecedent pairs in the rule structure are connected by a logical 'AND'. All the rules are then aggregated using a max-operation.

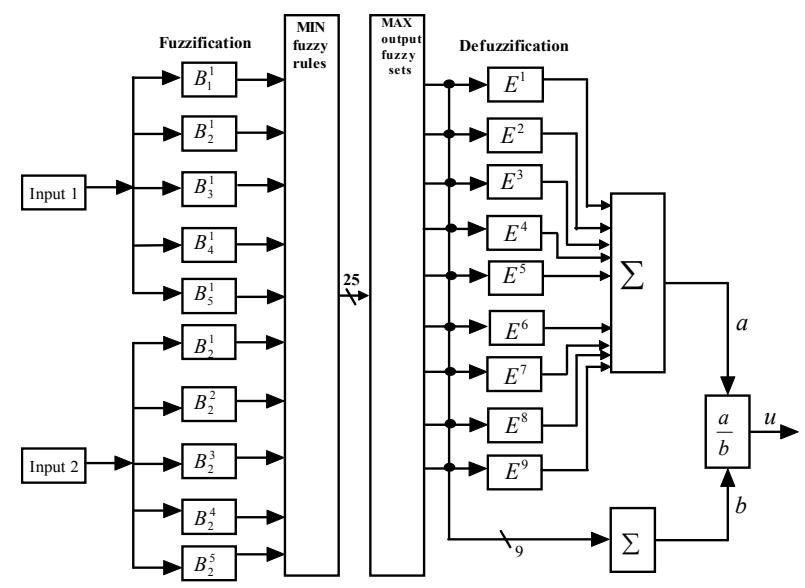

Figure 6 Block diagram of the operations in a Fuzzy Logic Controller

of

defuzzification technique lies in the implementation stage. The weighted average method is viewed to be an appropriate technique for systems involving hardware implementation. Due to the fact that the output membership functions are symmetrical in nature, the mean of the fuzzy sets can be used as weightings for the defuzzification process. This technique requires several multiply-by-a-constant operations and only one division process. Rule base moulds the functionality of an FLC. The rules are most likely to be formulated based on some level of human understanding of the plant.. The design of the FLC in this paper is based on PI controllers .The rule base is constructed from the control law of a PI system.

\subsection{PI control}

The proportional-integral (PI) controller is a wellknown system in control engineering. It is, in essence, a lag compensator characterised by the transfer function

$$
\mathrm{G}(\mathrm{s})=\mathrm{K}\left(1+\frac{1}{\mathrm{~T} . \mathrm{s}}\right)
$$

where:

$G(s)$ is the gain; $K$ is the control parameter; $T$ is the time constant. The control law is given by the equation

$$
u_{P I}=K_{p} \cdot e+K_{I} \frac{1}{T} \int_{0}^{t} e . d t
$$

where:

$u$ is the control signal; $e$ is the error, given by $e=$ (input value) (reference value).

Differentiating (6) gives

$\frac{d u}{d t}=K_{p} \frac{d e}{d t}+K_{I} . \mathrm{e}$

In discrete-time systems, (7) can be written as $\mathrm{u}(\mathrm{kt})-\mathrm{u}(\mathrm{kT}-\mathrm{T})=K_{p} .\{e(K T)-e(k T-T)\}+K_{I} . e(k T)$

$\Delta u=K_{p} . \Delta e+K_{I} \cdot e$

where:

$\Delta u$ is the change in $u$ over one sampling period; $\Delta e$ is the change in $e$ over one sampling period.

The values of controller parameters are found from $\mathrm{Z}-\mathrm{H}$ tuning method. From the values found are $\mathrm{K}_{\mathrm{p}}=0.12$ and $\mathrm{K}_{\mathrm{i}}=0.0201$.

\subsection{PI-like fuzzy control}

At this stage, the control law in (8) is not in fuzzy terms. In order to design a fuzzy controller based on the PI control structure, the following definitions are made:

Let $E$ be the linguistic variable for the error $e ; \Delta E$ be the linguistic variable for the change of error $\Delta e$

$U$ be the linguistic variable for the control output $u$. The maximum range of motor is $+/-1500 \mathrm{rpm}$. The possible error range is -750 to 750 . The universe of Discourse of the change in error is based on experiment data from conventional controller which gives the range of error is +/- 150. Ouput of the controller ranges from $+/$ - 8. Linguistic variables for $E, \Delta E, U$ are defined as

$L E=\{$ Negative Big(-750rpm), Negative(-500rpm), Zero(0), Positive(500rpm), Positive Big(750 rpm)\}

$L \Delta E=\{$ Negative Big(-150rpm ), Negative(-75 rpm), Zero(0), Positive(75), Positive Big(150)\}

$L U=\{$ Negative very Big(-8), Negative Big(-6), Negative(-4), Negative Small(-2), Zero(0), Positive Small(2), Positive(4), Positive Big(6), Positive very Big(8) \}

The corresponding PI control law in IF-THEN rules has the form:

$R^{K}:$ IF $x_{1}$ is $A_{1}^{K}$ AND $x_{2}$ is $A_{2}^{K}$, THEN $y$ is $C^{K}$

where: 
$A_{1}^{K}$ can take any linguistic value in the set $L E ; A_{2}^{K}$ can take any linguistic value in the set $L \Delta E$

$C^{K}$ can take any linguistic value in the set $L U$.

To implement this design into the FLC, let:

$x 2=\Delta E$

- $\quad\left\{\boldsymbol{B}_{i}^{1}, \boldsymbol{B}_{i}^{2} \boldsymbol{B}_{i}^{3} \boldsymbol{B}_{i}^{4} \boldsymbol{B}_{i}^{\mathbf{E}}\right\}=\{$ Negative Big(NB), Negative(N),

Zero(Z), Positive(P), Positive $\operatorname{Big}(\mathrm{PB})\}$, for $i=1,2$

$\left\{D^{1}, D^{2}, D^{3}, D^{4}, D^{5}, D^{6}, D^{7}, D^{8}, D^{9}\right\}=\{$ Negative very Big(NVB)

,Negative Big(NB), Negative(N), Negative Small(NS),

Zero(Z), Positive Small(PS), Positive(P), Positive Big(PB),

Positive very Big (PVB)\}.

\begin{tabular}{|c|c|c|c|c|c|}
\hline & $\begin{array}{c}\text { NB } \\
\left(B_{Z}^{1}\right)\end{array}$ & $\begin{array}{c}\mathbf{N} \\
\left(B_{2}^{2}\right)\end{array}$ & $\begin{array}{c}\mathbf{Z} \\
\left(B_{2}^{3}\right)\end{array}$ & $\begin{array}{c}\mathbf{P} \\
\left(B_{2}^{4}\right)\end{array}$ & $\begin{array}{c}\text { PB } \\
\left(B_{2}^{5}\right)\end{array}$ \\
\hline $\begin{array}{c}\text { NB } \\
\left(B_{1}^{1}\right)\end{array}$ & $\begin{array}{l}\text { NVB } \\
\qquad \mathrm{R}^{1}\end{array}$ & $\begin{array}{l}\text { NB } \\
\mathrm{R}^{2}\end{array}$ & $\begin{array}{l}\mathrm{N} \\
\mathrm{R}^{3}\end{array}$ & $\begin{array}{l}\text { NS } \\
\qquad \mathrm{R}^{4}\end{array}$ & $\begin{array}{l}\mathrm{Z} \\
\mathrm{R}^{5}\end{array}$ \\
\hline $\begin{array}{c}\mathbf{N} \\
\left(B_{1}^{2}\right)\end{array}$ & $\begin{array}{l}\text { NB } \\
\mathrm{R}^{6}\end{array}$ & $\begin{array}{l}\mathrm{N} \\
\mathrm{R}^{7}\end{array}$ & $\begin{array}{l}\text { NS } \\
\qquad \mathrm{R}^{8}\end{array}$ & $\begin{array}{l}\mathrm{Z} \\
\mathrm{R}^{9}\end{array}$ & $\begin{array}{l}\text { PS } \\
\qquad \mathrm{R}^{10}\end{array}$ \\
\hline $\begin{array}{c}\mathbf{Z} \\
\left(B_{1}^{3}\right)\end{array}$ & $\begin{array}{l}\mathrm{N} \\
\mathrm{R}^{11}\end{array}$ & $\begin{array}{l}\text { NS } \\
\qquad \mathrm{R}^{12}\end{array}$ & $\begin{array}{l}\mathrm{Z} \\
\mathrm{R}^{13}\end{array}$ & $\begin{array}{l}\text { PS } \\
\qquad \mathrm{R}^{14}\end{array}$ & $\begin{array}{l}\mathrm{P} \\
\mathrm{R}^{15}\end{array}$ \\
\hline $\begin{array}{c}\mathbf{P} \\
\left(B_{1}^{4}\right)\end{array}$ & $\begin{array}{l}\text { NS } \\
\qquad \mathrm{R}^{16}\end{array}$ & $\begin{array}{l}\mathrm{ZS} \\
\qquad \mathrm{R}^{17}\end{array}$ & $\begin{array}{l}\text { PS } \\
\qquad \mathrm{R}^{18}\end{array}$ & $\begin{array}{l}\mathrm{P} \\
\mathrm{R}^{19}\end{array}$ & $\begin{array}{l}\text { PB } \\
\qquad \mathrm{R}^{20}\end{array}$ \\
\hline $\begin{array}{c}\text { PB } \\
\left(B_{1}^{5}\right)\end{array}$ & $\begin{array}{l}\mathrm{Z} \\
\mathrm{R}^{21}\end{array}$ & $\begin{array}{l}\mathrm{PS} \\
\mathrm{R}^{22}\end{array}$ & $\begin{array}{l}\mathrm{P} \\
\mathrm{R}^{23}\end{array}$ & $\begin{array}{l}\mathrm{PB} \\
\mathrm{R}^{24}\end{array}$ & $\begin{array}{l}\text { PVB } \\
\qquad \mathrm{R}^{25}\end{array}$ \\
\hline
\end{tabular}

Table3 FAM table for FLC design

Figure 7 shows a block diagram demonstrating the implementation of the FLC in a Speed control of DC motor .In this application, the input interface converts the output of the speed sensor into error and change of error which are used as the two inputs to the FLC.

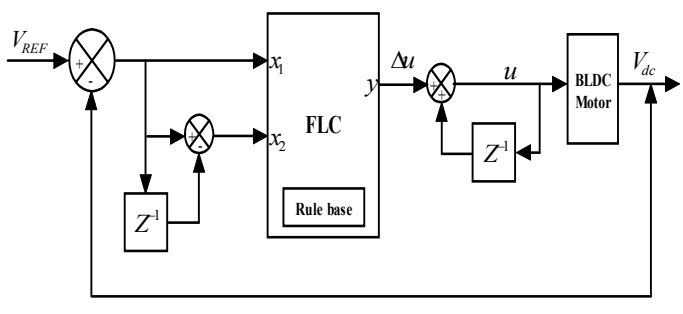

Figure7 Overall block diagram of FLC based control system for BLDC motor

Another interface converts the output into the required value for the plant. The characteristics of the interfacing blocks can be described by the following equations:

Input interface:

$e=V_{\mathrm{REF}}-V_{\mathrm{dc} ;} \quad x 1=e \quad ; x 2=x 1-x 1 z^{-1}$

Output interface:

$\Delta \mathrm{u}=y ; \quad u=\Delta \mathrm{u}+u z^{-1}$

\section{Experimental setup}

The overall block diagram of BLDc motor speed control is shown in figure 8. The BLDC motor is chosen in this work whose parameters are shoe in table 4 .

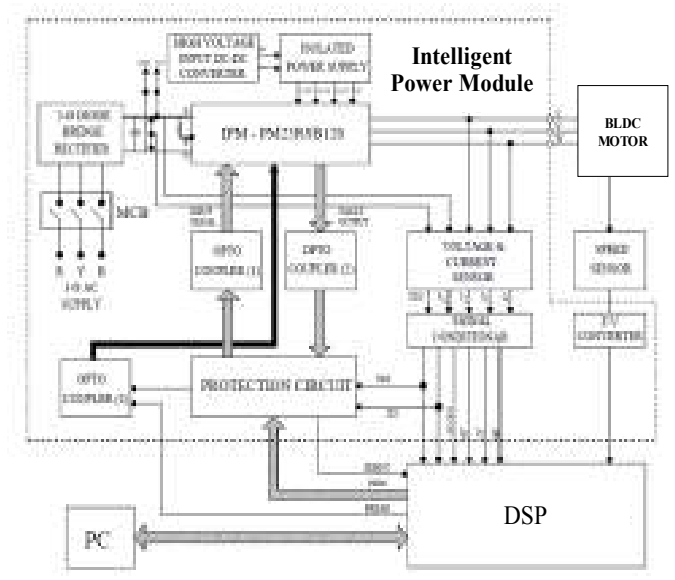

Figure 8 Overall block diagram of speed control of BLDC motor

\begin{tabular}{|l|c|l|}
\hline \multicolumn{1}{|c|}{ Parameter } & Symbol & \multicolumn{1}{c|}{ Data } \\
\hline Armature Inductance & $\mathrm{L}$ & $1.13 \mathrm{mH}$ \\
\hline Armature resistance & $\mathrm{R}$ & $3.21 \Omega$ \\
\hline Rotor Inertia & $\mathrm{J}$ & $0.932 \times 10^{-11} \mathrm{Kg} \cdot \mathrm{m}^{2}$ \\
\hline Damping Constant & $\mathrm{K}_{\mathrm{a}}$ & $1.099 \times 10^{-12} \mathrm{~N} . \mathrm{m} . \mathrm{s} / \mathrm{rad}$ \\
\hline Back Emf Constant & $\mathrm{K}_{\mathrm{e}}$ & $0.593 \times 10^{-4} \mathrm{~V} . \mathrm{sec}$ \\
\hline Torque constant & $\mathrm{K}_{\mathrm{t}}$ & $0.0145 \times 10^{-6} \mathrm{n} . \mathrm{m} / \mathrm{A}$ \\
\hline
\end{tabular}

Table4 Parameters of the test BLDC motor

\subsection{Intelligent power module :}

Intelligent power modules (IPMs) are advanced hybrid power devices that combine high speed, low loss IGBTs with optimized gate drive and protection circuitry. The power stage consists of a Variable source converter (VSC) fed drive. It has two stages of power conversion, a rectifier and converter. The rectifier converters a fixed voltage $\mathrm{AC}$ to either fixed or adjustable DC voltage. The converter is constituted of solid state switches(IGBT), that switch the DC power on and off to produce a controllable and desired DC voltage .FPGA generates firing pulses for the power switches in the converter. IPM 
consists of 1. Intelligent Power Module 2. Voltage and Current Sensor 3. Signal Conditioner 4. Protection Circuit 5. Optocoupler 6. Three phase Diode Bridge Rectifier 7. Speed Sensor 8. Frequency to Voltage converter.IPM has sophisticated built-in protection circuits that prevent the power devices from being damaged. The protection schemes available in IPM are self protection, over temperature protection, over current protection, short circuit protection. Three phase diode bridge rectifier is used to give rectified DC voltage to IPM. Output voltages and current of IPM are not directly fed to control circuits ,because output voltage of IPM is high, but control circuit is operated in minimum voltage $(5 \mathrm{v})$.Hall effect transducers are used for these type of conversion .Signal conditioning circuits are used to give the reference signal of current and voltage to the protection circuit as well as to the ADC of DSP kit. Optocoupler is used to isolate the control circuit from power circuit. Speed of the Dc motor is sensed by optical encoder which gives the output in terms of frequency proportional to speed. By means of Frequency to voltage converter, sensor output is converted in to voltage .

Figure 8 shows the BLDC motor. The speed of the motor is measured by means of Hall sensor encoder and given as input to $\mathrm{ADC}(\mathrm{AD} 7266)$. The $\mathrm{ADC}$ used here is $12 \mathrm{bit}$, high speed, low power, successive approximation ADC and features throughput rates up to 2 MSPS. The set speed is assigned to motor by toggle switches according to the requirement. Once this is done the ADC data will be read and Fuzzy Logic Controller implemented will calculate output value and the output of controller in term changes the duty cycle of PWM to increase or decrease the speed.IPM Module consists of Switching power converters are used in most BLDC motor drives to deliver the required energy to the motor. The energy that a switching power converter delivers to a BLDC motor is controlled by Pulse Width Modulated (PWM) signal applied to the gate of a power transistor coming from PWM module DSP kit. once the current speed equals the set speed, the motor starts running at the set speed. Again to change the set speed, the above procedure is repeated by changing the toggle switch position. As the set speed is varied, the ADC voltage also varies. It is observed that the current speed, which is displayed, on the 'on board' LCD display equals the set speed value. Figure. 9 shows the Photograph of the experimental setup and working model of DSP based BLDC motor speed control system

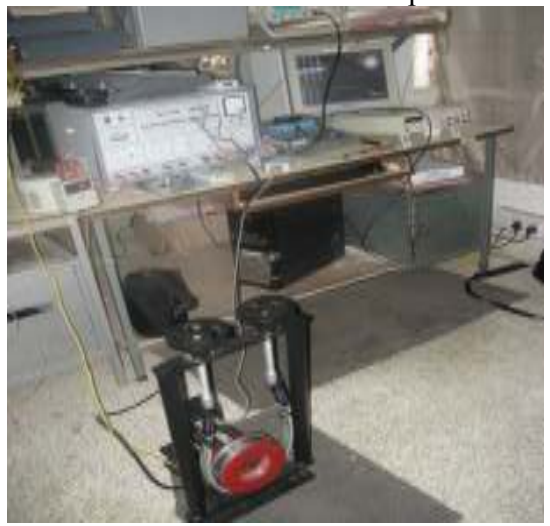

Figure 9 Real time experimental setup

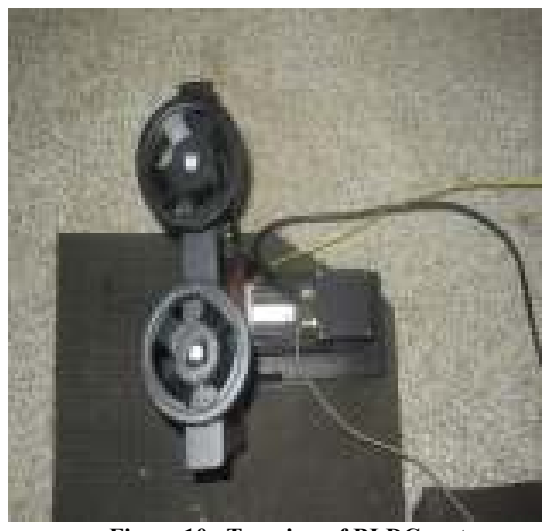

Figure 10 Top view of BLDC motor

\section{Results and Discussion}

The servo responses of the PI controller and FLC shown in Figure 13 and Figure 14. The set point is varied from $1700 \mathrm{rpm}$ to $2500 \mathrm{rpm}$.For the PI controller (shown in figure 13), set point tracking performance is characterized by lack of smooth transition between set point, as well as presence of overshoot and higher rise time. From figure 14 we can observe that the FLC having less oscillation, zero overshoots, less rise time. From the figure 14 and figure 15, it can be seen that FLC performs significantly better than PI controller. The FLC is used to control the speed of the motor while applying a load change of $+10 \%$. The motor is also run with a PI controller while applying the same load changes. The variations in speed with time for $10 \%$ load change for PI controller and FLC is shown in Figure 15 and Figure 16. The FLC is able to compensate for the load changes considerably better than PI controller . Figure11 and Figure 12shows PWM output and current output

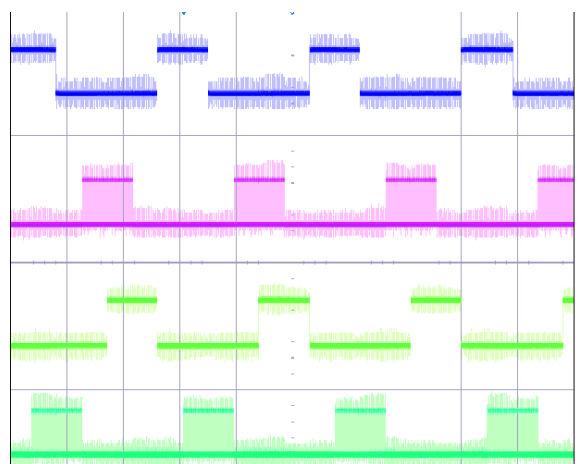

Figure 11: PWM output of IPM

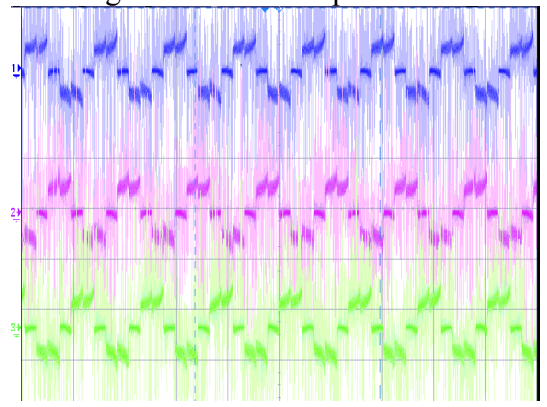

Figure 12 current output of BLDC motor 


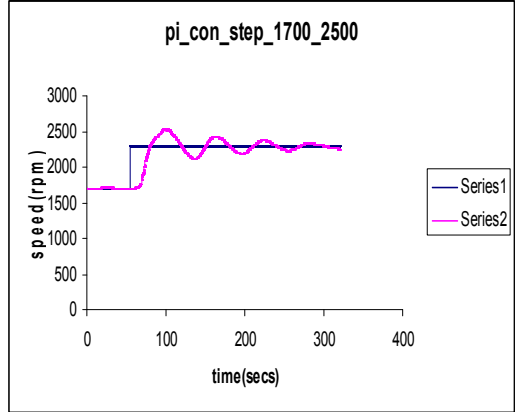

Figure13 Servo response of PI controller for a set point change from $1700 \mathrm{rpm}$ to2500rpm

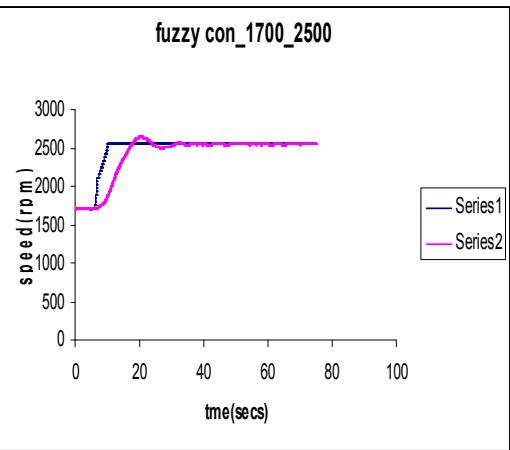

Figure14 Servo response of FLC for a set point change from $550 \mathrm{rpm}$ to1100rpm

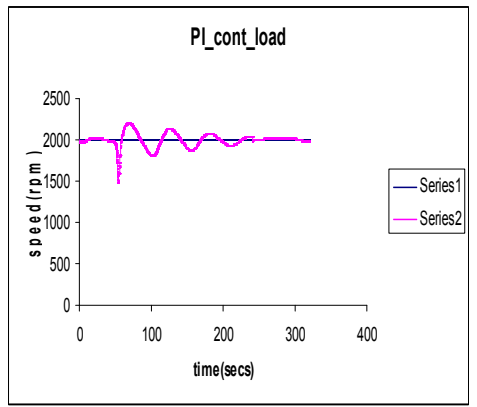

Figure 15 Regulatory response of PI controller under $+10 \%$ $+10 \%$ change in speed as load

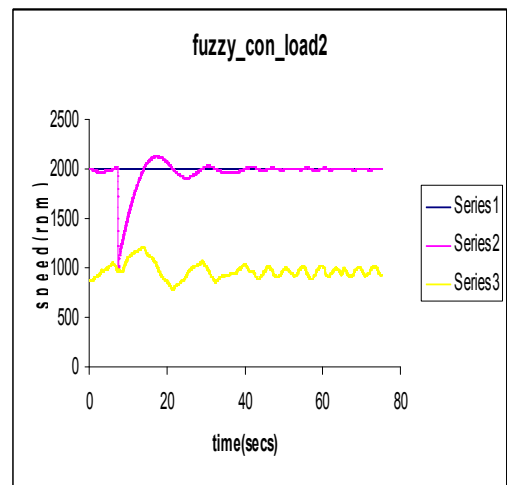

Figure16 Regulatory response of FLC under under $+10 \%$ change in load

\section{CONCLUSION}

This paper presents an approach for the implementation of a fuzzy logic controller for BLDC motor on an DSP using Vissim.. The implementation of the fuzzy logic controller is very straightforward by coding each component of the fuzzy inference system in vissim according to the design specifications. The design of the FLC is highly flexible as the membership functions and rule base can be easily changed. Moreover the performance of FLC is compared with PI controller for set point change and load change. The performance FLC was much superior than conventional PI controller and FLC is able to compensate load changes better than PI controller. By simply changing some parameters in the codes and design constraint on the specific synthesis tool, one can experiment with different design circuitry to get the best result in order to satisfy the system requirement. The FLC can also be used for control purposes in other applications.

\section{REFERENCES}

[1] P.Pillay and R.krrishnan. 'Modelling, simulation and analysis of a Permanent magnet brushless Dc motor drive'.IEEE trans.Ind Applicant., Vol26,pp124-129,2002

[2]Lee, J.: 'On Methods for Improving Performance of PI-Type Fuzzy Logic Controllers', IEEE Trans. Fuzzy Systems, vol. 1, no. 4, Nov. 1993, pp. 298-302.

[3]Mudi, R.K., Pal, N.R.: 'A Robust Self-tuning Scheme for PIand PD-type Fuzzy Controllers', IEEE Trans. Fuzzy Systems, vol. 7, no. 1, Feb. 1999, pp. 2-16.

[4]Jong-BaeLee,Tae-Bin Im,Ha-Kyong Sung, Young-ouk kim,"A Low cost speed control system of Brushless DC motor using Fuzzy logic",IEEE Trans.Ind Application,vol 2,1999,pp433-436.

[5] H. Ying, "Fuzzy Control and Modeling, Analytical Foundations and Applications", Institute of Electrical and Electronic Engineers Inc., USA, 2000

[6] K. M. Passino and Stephen Yurkovich, "Fuzzy Control", Addison-Weslwey Longman Inc., USA, 1998.

[7]Neural and fuzzy logic control of DRIVES AND Powersystems,M.NCirstea,A.Dinu,J.G.Khor,M.McCormick ,Newnes Publications,2002

[8] Bohdan Butkiewicz "About Robustness of Fuzzy Logic PD and PID Controller under Changes of Reasoning Methods" , Institute of Electronic Systems, Warsaw University of Technology , 2002

[9] Jun-UK chu,In-Hyuk Moon,Gi-won choi,Jei-chenong Ryu,Mu-seony Mun, "Design of BLDC motor controller for electric power whell chair", Mechatronics, 2004,ICM'04,Proceedings of the IEEE international conference.

[10]VisSim User's Guide,By Visual Solutions,Inc.

[11]TMSC320F2812 - User's Guide, Texas Instruments, Inc., 2008. 